\title{
Simulation of Friction Stir Processing in 304L Stainless Steel
}

\author{
M.P. Miles ${ }^{1 a}$, T.W. Nelson ${ }^{2}$, F.C. Liu ${ }^{2}$, C. Gunter ${ }^{1}$, and L. Fourment ${ }^{3}$ \\ ${ }^{1}$ Manufacturing Engineering Technology, Brigham Young University, Provo, UT 84602, USA \\ ${ }^{2}$ Mechanical Engineering, Brigham Young University, Provo, UT 84602, USA \\ ${ }^{3}$ Mines ParisTech, Centre de Mise en Forme des Materiaux (CEMEF), 06904 Sophia-Antipolis Cedex, France
}

\begin{abstract}
A major dilemma facing the nuclear industry is repair or replacement of stainless steel reactor components that have been exposed to neutron irradiation. When conventional fusion welding is used for weld repair, the high temperatures and thermal stresses inherent in the process enhance the growth of helium bubbles, causing intergranular cracking in the heat-affected zone (HAZ). Friction stir processing (FSP) has potential as a weld repair technique for irradiated stainless steel, because it operates at much lower temperatures than fusion welding, and is therefore less likely to cause cracking in the HAZ. Numerical simulation of the FSP process in 304L stainless steel was performed using an Eulerian finite element approach. Model input required flow stresses for the large range of strain rates and temperatures inherent in the FSP process. Temperature predictions in three locations adjacent to the stir zone were accurate to within $4 \%$ of experimentally measure values. Prediction of recrystallized grain size at a location about $6 \mathrm{~mm}$ behind the tool center was less accurate, because the empirical model employed for the prediction did not account for grain growth that occurred after deformation in the experiment was halted.
\end{abstract}

\section{Introduction}

The nuclear industry is facing challenges in repair or replacement of stainless steel reactor components, which have been exposed to neutron irradiation. Irradiated stainless steel contains helium, which forms primarily by $\mathrm{n} / \alpha$ reactions with alloying elements nickel and boron [16]. Helium gas is insoluble in metals, so it precipitates and forms bubbles (at the nanoscale), nucleating at dislocations, point defects, and grain boundaries [4]. When conventional fusion welding is used for weld repair, the high temperatures and thermal stresses inherent in the process enhance the growth of helium bubbles, causing intergranular cracking in the heataffected zone (HAZ) [6-8].

Repair of nuclear components encompasses both the replacement of a failed component, in which case a new component must be joined to existing structures, and the in situ repair of arc welds that have developed stress corrosion cracks in service $[2,9,10]$. In both cases the issue of helium embrittlement, accelerated by the temperatures and stresses of fusion welding, presents a serious difficulty that must be overcome. While low heat input laser welding can be a partial solution to the problem [7], reactors with 30-40 years of service may have irradiated components which cannot be repaired by any of the conventional methods [11]. It is anticipated that many nuclear reactors will function for up to 80 years [12], so the repairability of irradiated stainless steel is of great importance to this industry.
Friction stir processing (FSP) is similar to friction stir welding (FSW), except that its purpose is not to join parts together, but to modify material microstructures and properties. The repair of a stress corrosion crack in an existing weld could be done by passing a tool along an existing weld or HAZ and "healing" the crack. The process of FSP is shown in Figure 1.

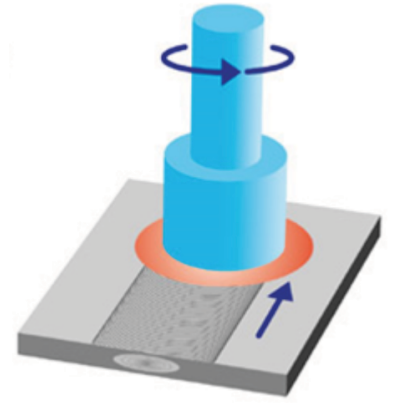

Figure 1. FSP could be used to repair a crack by processing an existing arc weld.

Much of the prior work done in FSW can be applied to FSP. Both FSW and FSP have been studied extensively for their ability to create favorable properties in metal alloys [13-19], most of which have been aluminum alloys. While we have not found research literature on the use of FSP to "heal", or repair, stress corrosion cracks in existing welds, one study by Sterling demonstrated that FSP can be used to process over existing arc welds in austenitic stainless steel, to enhance the mechanical properties of the weld [20]. For stress corrosion crack

\footnotetext{
a Corresponding author: mmiles@byu.edu
} 
repair of irradiated stainless steel, lower peak temperatures would favor the use of FSP over fusion welding processes like GTAW, because the helium bubbles present in the material would have a lower driving force to diffuse to grain boundaries in the HAZ. But if FSP is a potential solution for weld repair of irradiated stainless steel, there remains the potential challenge of sigma phase and chromium carbide formation, which have been reported in friction stir welded $304 \mathrm{~L}$ stainless steel along the advancing side of the stir zone [21]. Although others have reported preferential etching along this same region of the stir zone, they also report large variability, depending on the welding conditions [20, 22]. Sigma and chromium carbide phases are well known to reduce the corrosion resistance of austenitic stainless steel [21-23], and need to be suppressed if FSP is to be employed for weld repair. Based on these prior studies it is thought that dynamic recrystallization during processing may be responsible for the precipitation of these phases in the stir zone.

Most modeling work of the FSW/FSP process has been done under the assumption of steady state conditions, using an Eulerian approach. Some representative prior work is found in [18, 24-27]. Other investigators have used an arbitrary Lagrangian-Eulerian (ALE) formulation, where the velocity of the mesh and the velocity of the material are coupled at the free boundary, allowing the position of the free surfaces to evolve, but decoupled inside the free boundary, where the mesh velocity and material velocities can be different. This allows for adjustment of the mesh in order to avoid excessive distortions [28-30]. In all of these cases the weld interface, or faying surface, is not included explicitly in the model. Rather, the plates to be joined are modeled as one solid part, referred to as a bead on plate approach. This reduces the numerical complexity of managing contact problem at an interface, while still allowing for the computation of temperatures and material flow patterns in the stir zone. In the current work, an Eulerian approach was used to simulate FSP of 304L stainless steel using a bead on plate model. This is computationally more efficient than an ALE approach, while effectively predicting temperatures in the stir zone as long as friction is properly modeled between the workpiece and the tool [29, 31, 32]. Predicted temperatures and strain rates were used to estimate recrystallized grain size at three different locations in the stir zone, and these estimates were compared to an FSP experiment on 304L plate.

\section{Experimental Methods}

FSP experiments were performed on $12 \mathrm{~mm}$ thick $304 \mathrm{~L}$ stainless steel using a tool speed of $250 \mathrm{rpm}$ and a feed rate of $100 \mathrm{~mm} / \mathrm{min}$. The tool had a pin length of $8 \mathrm{~mm}$ and a convex shoulder with a diameter of $25 \mathrm{~mm}$, as shown in Figure 2.

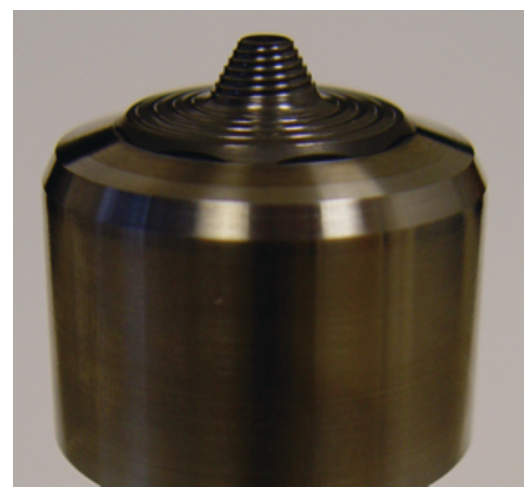

Figure 2. Friction stir processing tool, with convex shoulder and conical pin.

Initial average grain size for the as-received plate was 40 $\mu \mathrm{m}$ as measured by electron backscatter diffraction (EBSD). The composition of the plates that were processed is shown in Table 1.

Table 1. Composition of 304L stainless steel (wt \%).

\begin{tabular}{|c|c|c|c|c|c|c|c|c|}
\hline $\mathrm{C}$ & $\mathrm{Mn}$ & $\mathrm{P}$ & $\mathrm{S}$ & $\mathrm{Si}$ & $\mathrm{Cr}$ & $\mathrm{Ni}$ & $\mathrm{N}$ & $\mathrm{Fe}$ \\
\hline 0.08 & 2.0 & 0.05 & 0.03 & 0.75 & 18 & 10 & 0.1 & Balance \\
\hline
\end{tabular}

Holes were drilled in one side of the plate so that thermocouples could be embedded for temperature measurements. In addition to measuring temperatures in the plate, a thermocouple was also embedded in the FSP tool, near the outside diameter a few millimeters from the tool surface. The temperature in the tool was used to develop operating parameters for processing, prior to the experiment where plate temperatures were measured.

At the end of the FSP experiment, using a tool speed of $250 \mathrm{rpm}$ and a feed rate of $100 \mathrm{~mm} / \mathrm{min}$, the tool was retracted and ice water was immediately applied to the stir zone where the pin was removed. This was done in order to prevent grain growth, so that recrystallized grain size in different areas of the weld could be measured. Recrystallized grain sizes from the experiment were compared to predictions from the model.

\section{Model Description}

The modeling of FSP was done using a research version [28] of the Forge ${ }^{\circledR}$ software package. An Eulerian approach was used to simulate temperatures and material flow for $12 \mathrm{~mm}$ thick FSP of $304 \mathrm{~L}$ stainless steel. This approach assumes that contact conditions between the workpiece and the tool are known in advance, which is reasonable for friction stir processing, as long as the feeds (translation rate) and speeds (rotation rate) of the tool have been studied experimentally first and that the quality of the stir zone was verified (i.e. no voids were present).

The material flow stress was modeled as a function of strain, strain rate, and temperature using JMatPro [33] data for $304 \mathrm{~L}$ stainless steel. The flow stresses were modeled for a temperature range of $25-1300^{\circ} \mathrm{C}$, for strain rates from $10^{-3}$ to $10^{3} \mathrm{~s}^{-1}$, and for true strains of 0 to 4 . 
Friction conditions at the sliding interface between the workpiece and the tool were modeled by a viscoplastic Norton law:

$$
\tau_{f}=-\alpha_{f} K(T, \bar{\varepsilon})\left\|\Delta v_{s}\right\|^{q-1} \Delta v_{s}
$$

where $\alpha_{\mathrm{f}}$ is friction coefficient, $\mathrm{q}$ is sensitivity to the sliding velocity at the tool/workpiece interface, $\Delta \mathrm{v}_{\mathrm{s}}$ is the relatively sliding velocity between the tool and the workpiece, and $\mathrm{K}$ is a hardening parameter, function of temperature and effective strain, with the properties of the workpiece alloy.

Material flow prediction in the workpiece is based on a finite element discretization using an enhanced (P1+/P1) 4-node tetrahedron element, where equilibrium equations are solved iteratively until steady-state is reached in the velocity field. The velocity field and the temperature calculations are coupled, where flow stresses are updated after each iteration using the latest temperature estimates, until convergence. The final velocity field satisfies equilibrium conditions, and at the same time corresponds to the correct temperatures. The unilateral contact condition is applied to the workpiece surfaces by means of a nodal penalty formulation, where the FSP tool and the backing plate are considered to be rigid.

The heat generated by simultaneous rotation and translation of the tool in the $304 \mathrm{~L}$ workpiece causes temperatures to rise to approximately $1000^{\circ} \mathrm{C}$ at steady state. For the model, heat caused by plastic deformation is calculated as follows:

$$
\dot{q}_{p}=f \dot{\sigma \varepsilon}
$$

where $\mathrm{f}$ is the fraction of work converted into heat, taken as $0.9, \bar{\sigma}$ is effective stress, and $\dot{\bar{\varepsilon}}$ is effective strain rate. Heat caused by the frictional sliding at the tool/workpiece interface is given by:

$\dot{q}_{f}=\tau \cdot \Delta v_{s}$

where $\tau$ is the shear stress given by equation (1). Frictional heat is shared between the tool and the plate as a function of the effusivities of each, where the material with higher effusivity receives a greater portion of the frictional heat. The thermal conductivity, heat capacity, and density of both the tool and the $304 \mathrm{~L}$ plate were modeled as a function of temperature, over the range of temperatures from $25^{\circ} \mathrm{C}$ to $1300^{\circ} \mathrm{C}$.

The recrystallized grain size can also be estimated from the strains, strain rates, and temperatures that emerge from the steady-state FSP simulation. We follow the approach of Venugopal [34], who calculated average recrystallized grain size, using the following equation adapted to 304L stainless steel:

$$
d=20,560 \dot{\varepsilon}^{-0.3} e^{-0.25}\left(\frac{Q}{R T}\right)
$$

where $d$ is the recrystallized grain diameter $(\mu \mathrm{m}), \dot{\varepsilon}$ is strain rate, $\mathrm{Q}=310 \mathrm{~kJ} / \mathrm{mol}$, and $\mathrm{R}=8.314 \times 10^{-3} \mathrm{~kJ} / \mathrm{mol}-\mathrm{K}$.

\section{Results and Discussion}

The model consisted of a $304 \mathrm{~L}$ plate with 28,401 elements, a carbon steel backing plate with 23,270 elements, and a PCBN/W-Re tool with 23,270 elements. The heat transfer coefficient between the tool and the plate was $50,000 \mathrm{~W} / \mathrm{m}^{2}-{ }^{\circ} \mathrm{C}$, and between the $304 \mathrm{~L}$ and the carbon steel backing plate was $5,000 \mathrm{~W} / \mathrm{m}^{2}-{ }^{\circ} \mathrm{C}$. A tool holder imposed a boundary condition of $19^{\circ} \mathrm{C}$ on the shank of the tool, which simulated the cooled tool holder on the friction stir processing machine. Figure 3 shows the initial condition of the model.

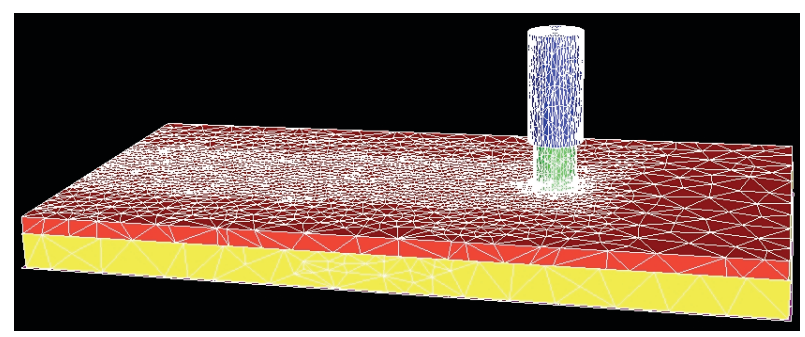

Figure 3. Model of friction stir processing of $304 \mathrm{~L}$ plate. The tool (green) is embedded in the $304 \mathrm{~L}$ plate (red). A constant temperature boundary condition of $19^{\circ} \mathrm{C}$ is imposed by the tool holder (blue) on the shank of the tool. The backing plate (yellow) is supported by a rigid support with a constant temperature boundary condition of $50^{\circ} \mathrm{C}$.

The tool speed was $250 \mathrm{rpm}$ while the feed rate was 100 $\mathrm{mm} / \mathrm{min}$. Friction coefficients were varied in order to accurately predict the steady-state temperatures of 3 thermocouples that were embedded in the $304 \mathrm{~L}$ plate. The model of the tool was not threaded, even though the physical tool had threads. However, the velocity boundary condition on the pin of the tool imposed a vertical component that essentially simulates action of the mechanical threads on the physical tool [28].

Thermocouples embedded in the 304L plate were $7 \mathrm{~mm}$, $9 \mathrm{~mm}$, and $11 \mathrm{~mm}$ from the centerline of the stir zone. Steady state temperatures were reached in the experiment after a translation of approximately $200 \mathrm{~mm}$. The comparison of experiment and simulation for the steadystate condition is shown in Figure 4.

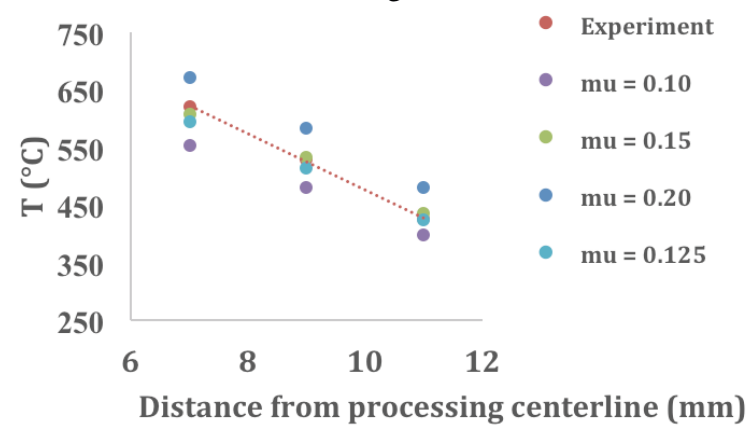

Figure 4. Comparison of predicted and experimentally measured temperatures at steady state. A friction coefficient of 0.125 provided the best prediction. 
A point by point comparison of temperatures in the $304 \mathrm{~L}$ plate and in the simulation is shown in Table 2.

Table 2. Comparison of predicted and experimentally measured temperatures at steady state, for a friction coefficient of 0.125 .

\begin{tabular}{|c|c|c|}
\hline $\begin{array}{c}\text { Distance from } \\
\text { center of stir zone }\end{array}$ & Experiment & Simulation \\
\hline $7 \mathrm{~mm}$ & $620^{\circ} \mathrm{C}$ & $595^{\circ} \mathrm{C}$ \\
\hline $9 \mathrm{~mm}$ & $529^{\circ} \mathrm{C}$ & $514^{\circ} \mathrm{C}$ \\
\hline $11 \mathrm{~mm}$ & $425^{\circ} \mathrm{C}$ & $423^{\circ} \mathrm{C}$ \\
\hline
\end{tabular}

Heat generated by friction at steady state was about 4.3 $\mathrm{kW}$, versus about $0.2 \mathrm{~kW}$ for the heat dissipated by plastic deformation. Therefore, about $96 \%$ of the heat generated by FSP was created by friction between the tool and the workpiece. This is consistent with prior simulation work in $304 \mathrm{~L}$. The steady state temperature profile for a friction coefficient of 0.125 is shown in figure 5 .

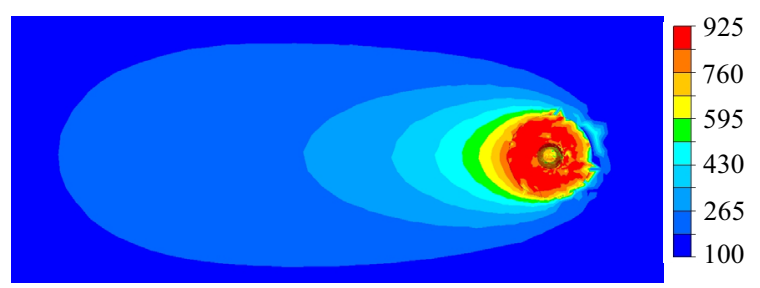

Figure 5. Temperature profile in $304 \mathrm{~L}$ plate at steady state (isovalues on right are in degrees Celsius). The maximum predicted temperature in the stir zone was $928^{\circ} \mathrm{C}$.

A specimen was taken from behind the keyhole left in the plate after the tool was retracted. After retracting the tool, ice water was poured over the keyhole in order to arrest grain growth so that recrystallized grain size could be measured. At a location about $6 \mathrm{~mm}$ behind the center of the tool the average grain size was about $7.4 \mu \mathrm{m}$. An EBSD image showing the grains at this location is shown in figure 6.

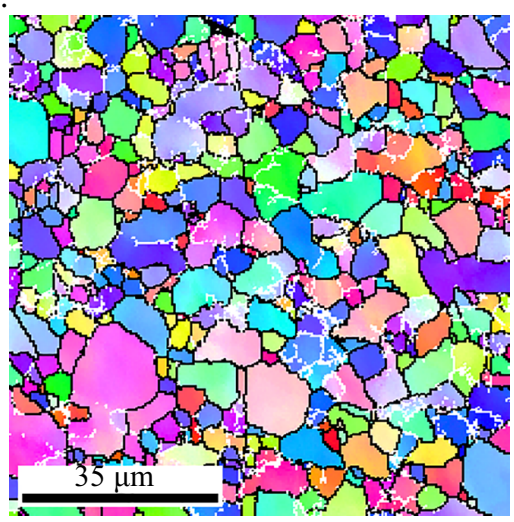

Figure 6. EBSD grain map from $6 \mathrm{~mm}$ behind the pin in the location where the tool was retracted, at the end of the experiment. Average recrystallized grain size at this location was $7 \mathrm{~mm}$, compared to an average grain size of $25 \mathrm{~mm}$ in the base material.

An estimate of the recrystallized grain size from the simulation was calculated from equation (4). The strain rate and temperature $6 \mathrm{~mm}$ behind tool center, at steady state, were $0.06 \mathrm{~s}^{-1}$ and $894^{\circ} \mathrm{C}$, respectively. Using these values the predicted grain size is $1.4 \mu \mathrm{m}$, which is only $20 \%$ of the measured grain size. However, the time that it took to cool the keyhole area at the end of the experiment was approximately 10 seconds, which is enough time for significant grain growth to occur, after deformation was halted. In order to more accurately predict final grain size the static grain growth that occurs when stirring is completed, and before cooling is applied, must also be modeled.

\section{Conclusions}

A steady state simulation of friction stir processing was carried out for $12 \mathrm{~mm}$ thick $304 \mathrm{~L}$ stainless steel. For a tool speed of $250 \mathrm{rpm}$ and a feed rate of $100 \mathrm{~mm} / \mathrm{min}$ the peak steady-state experimental temperatures at 7,9 , and $11 \mathrm{~mm}$ from the centreline of the stir zone were 620,529 , and $425^{\circ} \mathrm{C}$ respectively. Simulated temperatures in the same locations were 595,514 , and $423^{\circ} \mathrm{C}$. Thus, the greatest difference between simulation and experiment was $4 \%$, which represents a good level of accuracy. Temperatures and strain rates from the model were used to predict recrystallized grain size at a location about $6 \mathrm{~mm}$ behind the tool, at the end of the experiment when the plate was cooled rapidly with ice water. The predicted value was only about $20 \%$ of the measured grain size. The reason for the discrepancy is the grain growth that occurred during about 10 seconds between the end of the experiment and the application of the ice water. More accurate grain size predictions will require modelling of static grain growth that occurs after deformation has stopped.

\section{Acknowledgement}

This work was supported by National Science Foundation grant CMMI-1405508.

\section{References}

1. K. Asano, S. Nishimura, Y. Saito, H. Sakamoto, Y. Yamada, T. Kato, T. Hashimoto, J Nucl Mater, 264 (1999) 1-9.

2. W.R. Kanne, M.R. Louthan, D.T. Rankin, M.H. Tosten, Mater Charact, 43 (1999) 203-214.

3. K. Tsuchiya, H. Kawamura, G. Kalinin, J Nucl Mater, 283 (2000) 1210-1214.

4. S. Li, M.L. Grossbeck, Z. Zhang, W. Shen, B.A. Chin, Weld J, 90 (2011) 19S-26S.

5. M.H. Tosten, S.L. West, W.R. Kanne, B.J. Cross, Weld J, 86 (2007) 245S-252S.

6. Z. Feng, G. Wilkowski, Repair Welding of Irradiated Materials: Modeling of Helium Bubble Distributions for Determining Crack-Free Welding Procedures, 2002.

7. N. Yurioka, Y. Horii, Sci Technol Weld Joi, 11 (2006) 255-264.

8. W.R. Kanne, G.T. Chandler, D.Z. Nelson, E.A. Francoferreira, J Nucl Mater, 225 (1995) 69-75. 
9. C.A. Wang, M.L. Grossbeck, H. Aglan, B.A. Chin, J Nucl Mater, 239 (1996) 85-89.

10. C.A. Wang, M.L. Grossbeck, N.B. Potluri, B.A. Chin, J Nucl Mater, 233 (1996) 213-217.

11. E. Willis, personal communication, 2013.

12. S. Li, M.L. Grossbeck, Z. Zhang, W. Shen, B.A. Chin, Weld J, 90 (2011) 7.

13. Q. Yang, B.L. Xiao, Z.Y. Ma, Metall Mater Trans A, 43A (2012) 2094-2109.

14. F.Y. Tsai, P.W. Kao, Mater Lett, 80 (2012) 40-42.

15. N. Sun, D. Apelian, Jom-Us, 63 (2011) 44-50.

16. X.L. Feng, H.J. Liu, S.S. Babu, Scripta Mater, 65 (2011) 1057-1060.

17. F.C. Liu, Z.Y. Ma, Scripta Mater, 62 (2010) 125-128.

18. B.C. Liechty, B.W. Webb, International Journal of Machine Tools \& Manufacture, 48 (2008) 1474-1485.

19. R.S. Mishra, Z.Y. Ma, Materials Science and Engineering: R: Reports, 50 (2005) 1-78.

20. C.J. Sterling, T.W. Nelson, C.D. Sorensen, M. Posada, Research Report, Office of Naval Research, 2004, pp. 7.

21. S.H.C. Park, Y.S. Sato, H. Kokawa, K. Okamoto, S. Hirano, M. Inagaki, Scripta Mater, 49 (2003) 1175-1180. 22. C.D. Sorensen, T.W. Nelson, Proceedings of the 7 th International Conference on Trends in Welding Research, ASM, Pine Mountain, GA, 2005, pp. 441-446.

23. S.H.C. Park, Y.S. Sato, H. Kokawa, K. Okamoto, S. Hirano, M. Inagaki, Scripta Mater, 51 (2004) 101-105.

24. S. Perivilli, J. Peddieson, J. Cui, Journal of Manufacturing Science and Engineering-Transactions of the Asme, 131 (2008) 1-8.

25. J.H. Kim, F. Barlat, C. Kim, K. Chung, Metals and Materials International, 15 (2009) 125-132.

26. C. Cox, D. Lammlein, A. Strauss, G. Cook, Materials and Manufacturing Processes, 25 (2010) 1278-1282.

27. H. Atharifar, D.C. Lin, R. Kovacevic, Journal of Materials Engineering and Performance, 18 (2009) 339350 .

28. S. Guerdoux, L. Fourment, Modelling and Simulation in Materials Science and Engineering, 17 (2009) 143155.

29. M. Assidi, L. Fourment, S. Guerdoux, T. Nelson, International Journal of Machine Tools \& Manufacture, 50 (2010) 143-155.

30. L. Fratini, G. Buffa, Journal of Engineering Materials and Technology-Transactions of the ASME, 130 (2008)

31. S. Guerdoux, L. Fourment, M. Miles, T. Nelson, Proceedings of the Annual TMS Conference, Orlando, FL, 2007, pp. 83-88.

32. M. Miles, T. Nelson, L. Fourment, S. Guerdoux, Materials Science \& Technology 2008 - Joining of Advances and Specialty Metals, Pittsburgh, PA, 2008, pp. 2319-2330.

33. Sente Software Ltd., Surrey Technology Centre, 40 Occam Road GU2 7YG, United Kingdom, 2015.

34. S. Venugopal, P.V. Sivaprasad, Journal of Materials Engineering and Performance, 12 (2003) 674-686. 